\title{
FIRE DYNAMICS IN FAÇADE FIRE TESTS: Measurement, modeling and repeatability
}

\author{
Johan Anderson $^{\mathrm{a}}$, Lars Boström ${ }^{\mathrm{a}}$, Robert Jansson ${ }^{\mathrm{a}}$, and Bojan Milovanović ${ }^{\mathrm{b}}$ \\ ${ }^{a}$ SP Technical Research Institute of Sweden Fire Research, Brinellgatan 4, Box 857. S-501 15. Borås Sweden.Slovenia \\ ${ }^{\mathrm{b}}$ Faculty of Civil Engineering, Department of Materials, University of Zagreb, Croatia
}

\begin{abstract}
Presented is a comparison between full-scale façade tests where SP Fire 105 and BS 8414-1 were used regarding repeatability and the use of modelling to discern changes in the set-ups. Results show that the air movements around the test set-up (the wind) may have a significant impact on the tests and that the heat exposure to the façade surface will among other depend on the thickness of the test specimen. Also demonstrated was that good results could be obtained by modelling of the façade fire tests giving us the opportunity to use these methods to determine the effect of a change in the experimental setup.
\end{abstract}

Keywords: façade fire test, external fire, repeatability, FDS

\section{INTRODUCTION}

The risk of fire spreading from floor to floor via external walls has been evaluated for a long time with a number of different test methods. The different test methods have been proposed in order to evaluate different wall claddings, insulations and geometrical considerations, Babrauskas, 1996. The situation today is that a large number of different tests are used for classification of façade systems, ranging from small scale tests to full scale tests. Since each country has their own building regulation, there is a large spread in the requirements and how to determine the performance of the façade system, Strömgren, et al. 2013 and White et al. 2014. This paper includes a comparison of the result from six tests performed outdoors in accordance with BS 8414-1, and nine tests performed indoors using SP Fire 105. One of the main objectives of the work has been to investigate the repeatability obtained when performing large scale façade fire tests. There are many factors that can influence on the repeatability of a test method, and in this case the environment is of great importance.

There is a great demand for a standardized test method to be used in Europe. In order to introduce a European method it must be shown that it is repeatable and reproducible. This paper will display some data on the repeatability using two large scale test methods. In order to study the reproducibility the same method must be used at different laboratories, which is more complicated since each laboratory usually have the method used nationally (each country have their specific method) and to build a test set-up for other methods are very costly.

\section{FIRE TESTS}

\subsection{Zagreb tests}

Two series of tests have been carried out outdoors in Zagreb, Croatia, one in March 2014 and one in May 2014. The tests were made in accordance with BS 8414-1:2002, i.e. a large scale façade test method. In each test three façade rigs were used with different test specimens, i.e. three different façade systems. The three façades were prepared with different types of external thermal insulation composite systems (ETICS). The specimens were instrumented as defined in the standard. In addition to these measurements, temperatures were measured at different heights from the combustion chamber with different types of thermocouples. The test specimen extends $6 \mathrm{~m}$ above 
the combustion chamber and is $2.6 \mathrm{~m}$ wide with a return wall (wing) of similar height and $1.5 \mathrm{~m}$ wide. The fire exposure conditions represent an external fire source or a fully-developed fire in a room, venting through an opening such as a window aperture that exposes the cladding to the effects external flames. The square opening of the combustion chamber has side length of $2 \mathrm{~m}$ and the fire source is a wood crib with a nominal total heat output of $4500 \mathrm{MJ}$ over 30 minutes at a peak rate of $3 \pm 0.5 \mathrm{MW}$. Wall 1 consisted of noncombustible mineral wool insulation, Wall 2 of EPS insulation and fire stops at different heights of rock-wool insulation, and Wall 3 of EPS insulation. All three wall had an organic rendering on the surface and classified for the reaction to fire as B$\mathrm{s} 2, \mathrm{~d} 0$ or better.

The two tests were exactly the same, except the climate conditions since the tests were carried out outdoors. In the first test the temperature was around $15^{\circ} \mathrm{C}$ and the wind speed varied between 2 and $5 \mathrm{~m} / \mathrm{s}$. In the second test the temperature was around $25^{\circ} \mathrm{C}$ and the wind speed varied between 0 and $2 \mathrm{~m} / \mathrm{s}$. During the tests the weight of the fuel was measured by load cells. The initial weight of each wood crib is given in Table 1 . It can be noted that the initial weight differ considerably since the standard only prescribe the volume of wood to be used and it does not consider the large difference of density of wood. In Fig. 1 is the fuel consumption during the test shown. The fuel consumption has been calculated as the time derivative of the fuel weight throughout the test. The data indicate that the fuel consumption was much faster during the test in March 2014 when the wind speed was higher.

Table 1 Weight of wood cribs in the tests

\begin{tabular}{|c|c|c|c|}
\hline Test & Wall 1 & Wall 2 & Wall 3 \\
\hline March 2014 & $363 \mathrm{~kg}$ & $369 \mathrm{~kg}$ & $357 \mathrm{~kg}$ \\
\hline May 2014 & $395 \mathrm{~kg}$ & $437 \mathrm{~kg}$ & $445 \mathrm{~kg}$ \\
\hline
\end{tabular}

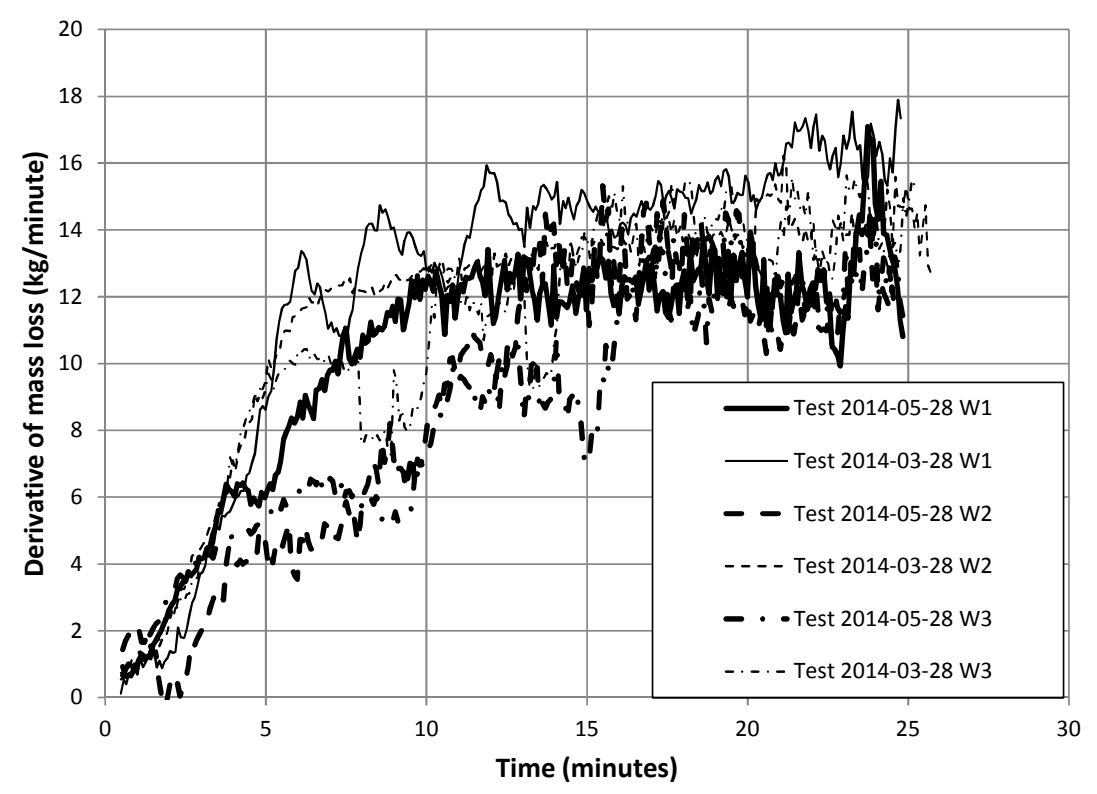

Fig. 1 Fuel consumption per time unit during the fire test where WX stands for Wall X. 


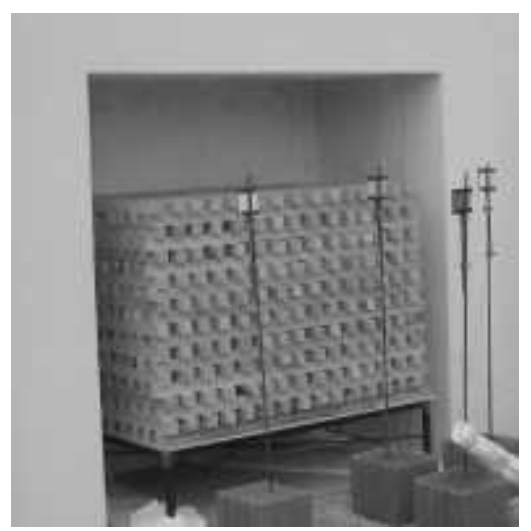

Fig. 2 Position of plate thermometers in front of the combustion chamber.

The heat exposure from the combustion chamber was measured by placing four additional plate thermometers in front of the chamber, three at a distance $0.5 \mathrm{~m}$, and one $1.0 \mathrm{~m}$ from the fire source, see Fig. 2. The plate thermometers were pointing towards the fire. The results from the measurements $0.5 \mathrm{~m}$ from the combustion chamber are presented in Fig. 3 as the mean value of the three plate thermometers. These measurements are closely correlated to the fuel consumption, i.e. in the tests with faster fuel consumption, the measured plate temperatures are higher.

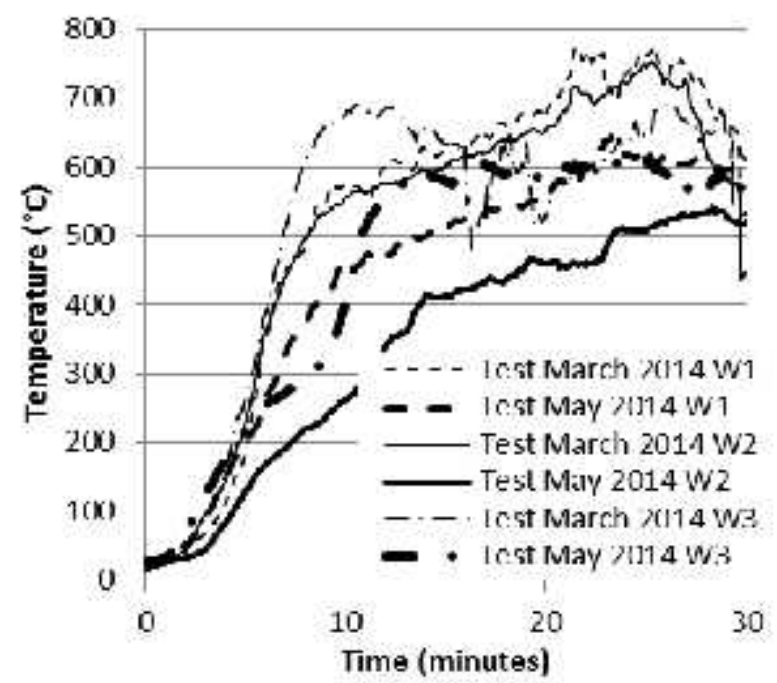

Fig. 3 Mean plate termometer temperature $0.5 \mathrm{~m}$ from the combustion chamber where WX stands for Wall $\mathrm{X}$.
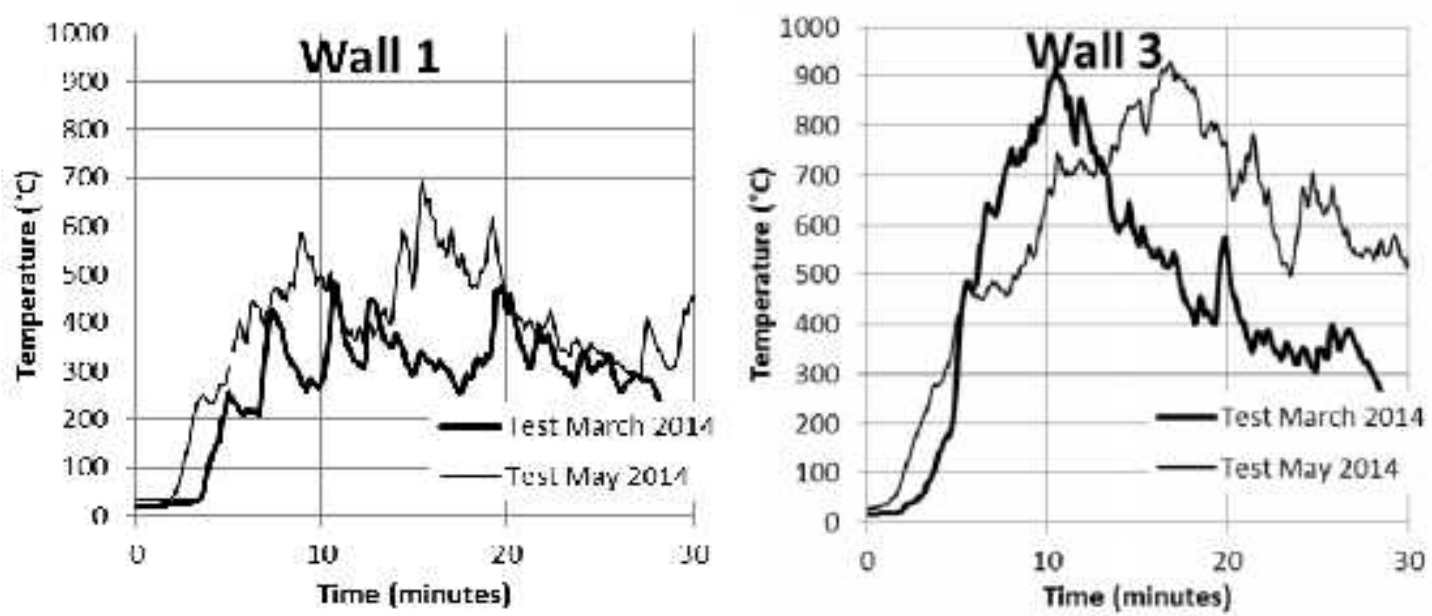

Fig. 4 Plate thermometer temperature $1.25 \mathrm{~m}$ above the combustion chamber, plate viewing outwards. 
The temperature was also measured with a plate thermometer $1.25 \mathrm{~m}$ above the top edge of the fuel chamber. This plate thermometer was placed $10 \mathrm{~cm}$ from the façade surface and pointing outwards, i.e. it measures the incident heat exposure to the façade. The measurements are generally unstable and the temperature fluctuates to a large degree. This is most probably due to the wind, and for Wall 3 the extra heat produced by the combustion of the EPS insulation.

\subsection{SP Fire 105 tests}

The SP Fire 105 test is carried out indoors in a fire testing hall, and thus the air movements are kept on a very low level. The method is similar to BS 8141-1 with respect to size, although it does not have the wing as the British method. Another difference is the fuel used. BS 8141-1 uses wood while SP Fire 105 used 601 heptane and the height of the combustion chamber is $710 \mathrm{~mm}$ in SP Fire 105 while it is $2000 \mathrm{~mm}$ in BS 8141-1. Nine tests are presented here, four tests of combustible insulation with a protecting render, three different wood façade systems with wood impregnated with fire retardants, one test with combustible insulation protected with bricks and one directly exposed insulation of phenolic resin. As in the Zagreb tests described above the thermal exposure has been measured $0.5 \mathrm{~m}$ from the combustion chamber using three additional plate thermometers not specified in the test method. The mean temperatures of these plate thermometers obtained in each test are presented in Fig. 5. The temperature varies between the different tests and one parameter that affects the measured plate temperature is the thickness of the test specimen.
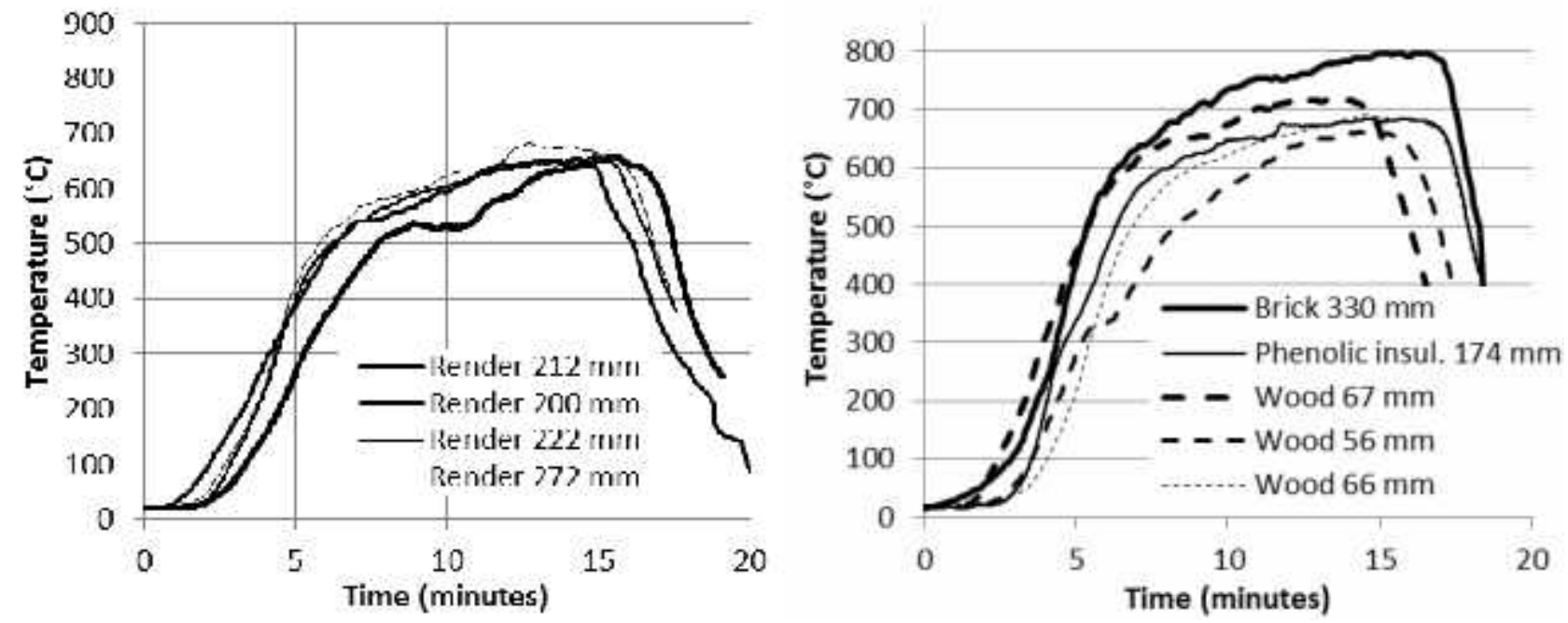

Fig. 5 Mean temperature $0.5 \mathrm{~m}$ from the combustion chamber

The temperature was also measured using a plate thermometer pointing outwards $2.1 \mathrm{~m}$ above the upper edge of the combustion chamber. The results are presented in Fig. 6. Since the test specimen in some cases contribute to the heat production the measured temperatures are not fully comparable. In the case with combustible insulation and rendering, the render have in some cases cracked open and thus combustible gases from the insulation will be released and add to the fire.

One test deviates from the other and that is the very thick façade with bricks. The measurements show that the plate thermometer temperature from the combustion chamber is higher than the other tests, and that the temperature $2.1 \mathrm{~m}$ above the combustion chamber is lower. This can to some extent be explained by the thickness of the façade system. The radiative heat depends on the thickness of flames. When the thickness of the façade increases, also the length for the flames to reach the façade surface increases, and thus the thickness of the flames seen by the plate thermometers. This underlines the fact that plate thermometers measure a type of effective surface temperature on a small reference specimen. This effective temperature is a much more representative quantitative measure of the thermal exposure on flat objects than the gas temperature. The thickness of the façade system affects the energy that will expose the façade surface since some of the energy will be absorbed by the bottom edge of the test specimen, i.e. the edge facing 
downwards and can be seen as an extension of the fuel chamber, as well as the floor. The thicker the specimen is the more energy will be absorbed by the bottom edge and the floor.
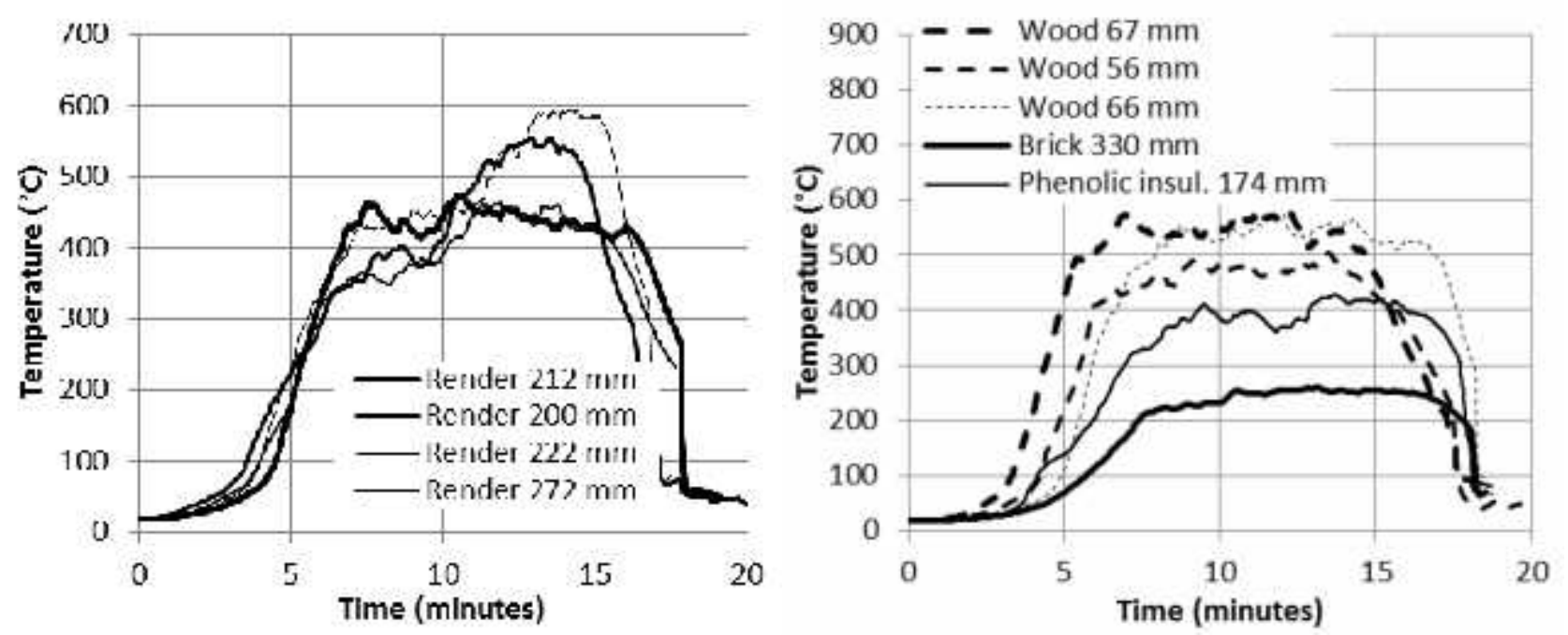

Fig. 6 Plate temperature $2.1 \mathrm{~m}$ above the combustion chamber, plate pointing outwards

\section{MODELLING OF FAÇADE FIRE TESTS}

In combination with the tests the fire dynamics was investigated by numerical means similar to what was done in two recent papers by Anderson and Jansson, 2013a and 2013b, where tests according to the test method SP Fire 105 were modelled. The numerical model was constructed in the CFD program Fire Dynamics Simulator (FDS) version 6.0, McGrattan, et al. 2013, with analogous geometry and instrumentation as in the described fire tests. In the previous work, good correspondence could be found between the shielded thermocouples in the FDS model compared with an experiment in the SP Fire 105 test rig where measured HRR were used as an input in the simulations. This confirmed that the design fire based on observations of the fire intensity during the test is valid. In all simulations a grid size of $5 \mathrm{~cm}$ cubes were used. A grid sensitivity study was made and it was deemed that a $5 \mathrm{~cm}$ grid was sufficient to reproduce most of the relevant features. In these simulations, see Fig. 7, generic material data for insulation materials are used for the façade material. The benefit of this kind of modelling is to be able to predict the effect on fire dynamics from geometrical changes in the test rig or test specimen. This makes it a valuable tool to optimize the design of the standard methods.
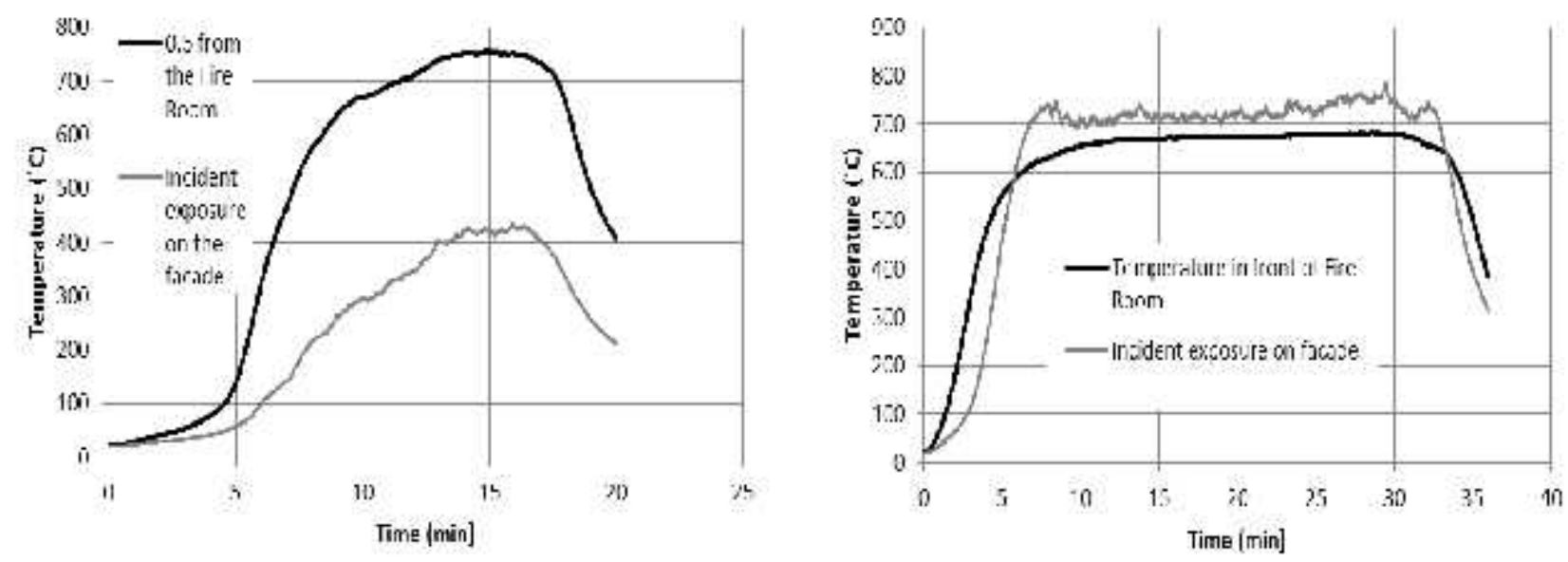

Fig. 7 The simulated results for SP Fire 105 (left) and for BS 8414 (right) set-ups.

Although some differences between the simulations and the measurements are found the general behaviour is captured. Moreover, the measurements specified in the standards are very well 
captured by these numerical models. However, in order for quantitative predictions thermal property data is needed of all components of the façade system. In all cases, the discrepancies found between the measured and simulated date occurred close to the fire source.

\section{DISCUSSION AND CONCLUSIONS}

The experimental results show that the repeatability is questionable in both BS 8141-1 and SP Fire 105. Both methods define an amount of fuel to be used, in BS 8141-1 a volume of wood and in SP Fire 105 a volume of heptane and the geometry of the combustion chamber. It is thus not possible to control the heat exposure to the façade surface, and it may be different from test to test due to factors such as air movements around the combustion chamber and geometry of the test samples. For example the thickness of the test specimen will have an effect since energy will be absorbed by the boundaries before the fire reaches the façade surface. It is also shown in the study that the air movements around the test set-up (the wind) may have a significant impact on the test. In order to ensure a robust, repeatable and reproducible test method for facades there are several issues that must be resolved. The heat exposure on the façade can for example be measured with plate thermometers, which is more linked with the thermal exposure of the façade surface compared to conventional thermocouples. A possible solution is to define a heat exposure curve, as in fire resistance testing, and use gas burners that can be regulated instead of using a defined amount of free burning fuel. Also a numerical tool for estimating the effects of design changes to the test methods was presented. The use of simulations may reduce the amount of large scale development testing which is inhibited by large costs.

\section{ACKNOWLEDGEMENTS}

The authors would like to thank for the support during the research to Fire Safe Europe and Croatian Association for Fire Protection, ZAG Slovenian National Building and Civil Engineering Institute, Laboratory for thermal measurements (LTM), Faculty of Civil Engineering, University of Zagreb, as well as the companies that donated the materials.

\section{REFERENCES}

Anderson, J., Jansson, R., Fire Dynamics in Façade Fire Tests: Measurement and Modeling, Proceedings of Interflam 2013, page 93, Royal Holloway College, University of London UK, (2013)

Anderson, J. and Jansson, R., Façade fire tests - measurements and modeling, MATEC Web of Conferences 9, 02003 (2013)

Babrauskas, V., Facade Fire Tests: Towards an International Test Standard, Fire Technology 32, 219-230 (1996)

British Standard BS 8414-1:2002, Fire performance of external cladding systems - Part 1: Test method for non-loadbearing external cladding systems applied to the face of the building (2002)

McGrattan, K., McDermott, R. Hostikka, S. Floyd, J., Fire Dynamics Simulator (Version 5) - user's guide. NIST Special Publication (2014)

SP FIRE 105, - Method for fire testing of façade materials, Dnr 171-79-360 Department of Fire Technology, Swedish National Testing and Research Institute (1994)

Strömgren, M. et al., Comparative analysis of façade regulations in the Nordic countries, MATEC Web of Conferences 9, 01003 (2013)

White, N. and Delichatsios, M., Fire Hazards of Exterior Wall Assemblies Containing Combustable Components, National Fire Protection Association (NFPA) Fire Protection Research Foundation Report (2014) 